\title{
The role of number and spacing of CS-US pairings in conditioned suppression*
}

\author{
JAMES P. JAMES' \\ Fort Hay's Kansas State College, Hay's. Kansas 67601 \\ and \\ LENNARD SHANGI. CLARE PANGMAN, and WALTER MOSTOWAY \\ Eniversity of Manitoba, Winnipeg. Manitoha. Canada
}

\begin{abstract}
In four studies, with rats as Ss. acquisition and. where appropriate, evtinction trials were presented against a baseline of ongoing licking. At shock intensities of $0.1,0.5,1.0$, or $2.0 \mathrm{~mA}$, acquisition performance was a function of number of CS-US pairings; spacing of trials (one or two per day) did not affect acquisition performance. Resistance to extinction could be predicted from terminal acquisition performance and reached a maximum after three CS-LS pairings.
\end{abstract}

The experiments reported here had two primary purposes: (a) to assess how spacing of trials affects the conditioning of response suppression, and (b) to investigate the relationship between number of acquisition trials and resistance to extinction. Previous research on spacing of trials was conducted by Brimer and Dockrill (1966), who found that groups receiving four trials a day acquired a CER slower in comparison to groups that received one or two daily trials. These findings led Beecroft (1967) to speculate that spacing CS-US pairings at one per day may produce optimal fear conditioning. Since a comparison between the one- and two-trials-a-day groups of Brimer and Dockrill was not warranted because each group was in a different experiment (see Brimer \& Dockrill, 1966, Footnote 3), the research reported here was designed in an attempt to make direct comparisons between the effects of one and two daily trials.

The research on number of CS-US pairings may be grouped according to the measures used to assess CER strength. Several investigators have used short, momentary tests of CER strength consisting of a single trial or a very limited number of trials. With these tests of momentary response strength, no relationship has been reported between strength of CER and 2, 6, or 12 CS-US pairings (Strouthes \& Hamilton, 1964); 8, 16, or 32 pairings (Strouthes, 1965); 4 or 16 pairings (Leaf \& Muller, 1965); and 1,2, or 4 pairings (Carlton \& Vogel, 1967). In contrast, Libby (1951) reported a curvilinear relation between CER strength and $0,5,10,20,40$, and 80 trials, with maximum conditioning occurring at 40

*This research was supported by Grant APA-223 from the National Research Council of Canada. The results were presented at the Midwestern Psychological Association meeting, Cleveland, May 1972.

$\div$ Requests for reprints should be sent to J. P. James, Department of Psychology, Western Illinois University, Macomb, Illinois 61455 . trials. Using a second kind of measure of CER strength, resistance to extinction, Kamin, Brimer, and Black (1963) found that strength of a CER was an increasing function of number of CS-US trials. Finally, performance during acquisition trials, as a measure of CER strength, typically yields a positive relation between number of pairings and strength of conditioned suppression. However, the recovery from suppression that results from lengthy acquisition training (Hendry \& Van Toller, 1965) or from the use of a specific intermediate shock intensity (Annau \& Kamin, 1961) suggests a curvilinear function relating number of pairings to CER strength.

\section{GENERAL METHOD}

\section{Subjects}

All Ss were male Holtzman albino rats, 90-120 days of age. Throughout each experiment, the animals were housed in individual cages where each had free access to Purina Lab Chow.

\section{Apparatus}

Three conditioning chambers were used, each consisting of a commercially manufactured Skinner box (Scientific Prototype A-100) set inside a ventilated, sound-attenuated enclosure (Lehigh Valley A-64). In place of the lever and foodcup, a drinking tube from a water bottle, filled with fresh tape water, could be remotely presented to or withdrawn from Ss. This drinking spout was made accessible to Ss through an opening in the center of one wall, $5 \mathrm{~cm}$ above the grid floor. The aperture at the drinking end of the tube was approximately $3.8 \mathrm{~mm}$ in diam. The response transducers were Grason-Stadler (E4690A-L) drinkometers. Tongue contacts with the drinking tube were recorded on electromechanical counters. Grid shock to each chamber was delivered by separate Grason-Stadler shock generators (E1064GS). The CS consisted of white noise from a Grason-Stadler (901B) noise generator. The CS intensity was measured and calibrated by a Bruel and Kjaer Model 2203 sound level meter set on the linear fast scale. Continuous illumination was provided by one GE 1829 incandescent lamp, operated at $18 \mathrm{~V} \mathrm{dc}$ and mounted at the end of the chamber opposite to the 


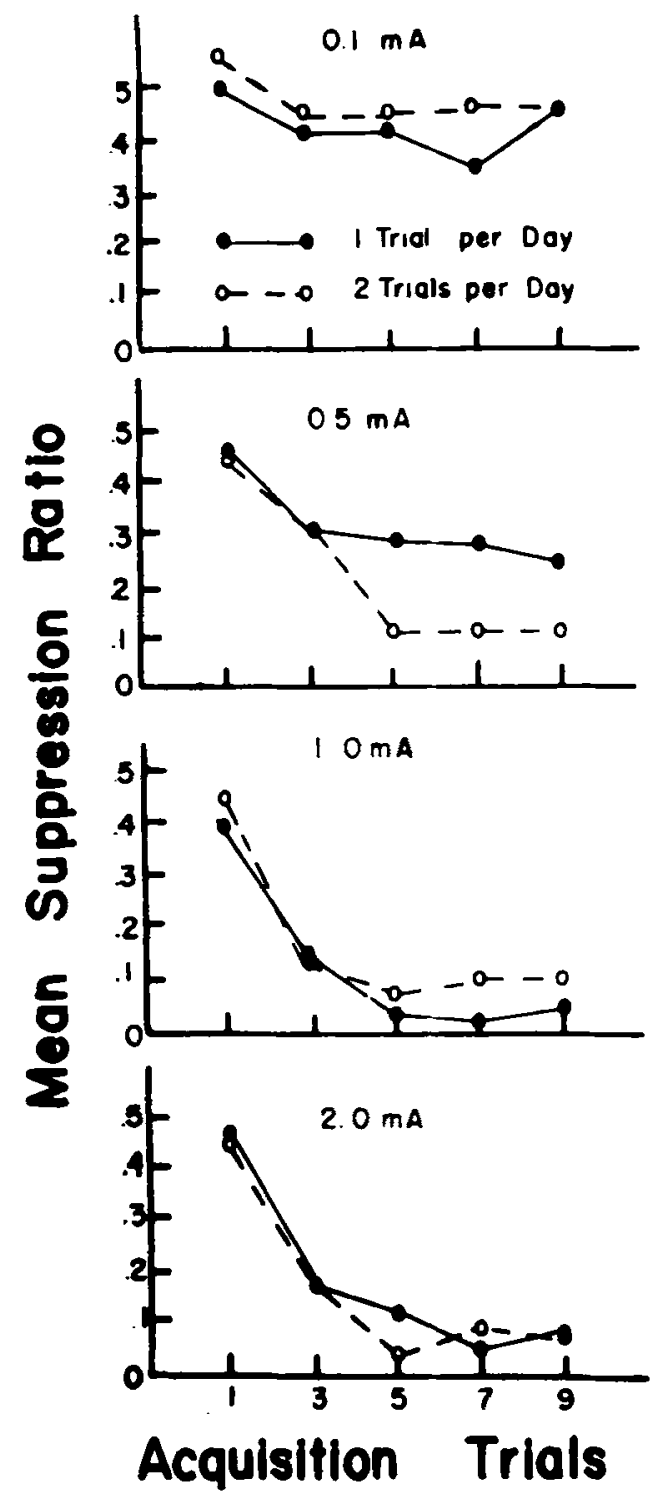

Fig. 1. Mean suppression ratios at each level of shock intensity across the odd-numbered acquisition trials as a function of daily trials.

drinking tube. Electromechanical programming and recording equipment was located in an adjacent room.

\section{Procedure}

In all experiments, Ss were run on successive days, without exception. All daily experimental sessions in the conditioning chambers were $10 \mathrm{~min}$ in length. During an initial eight daily sessions, $\mathrm{Ss}$ were adapted to the water deprivation schedule and to the conditioning boxes. During each of the final two adaptation sessions, $10 \mathrm{CS}$ familiarization trials were given. On subsequent sessions, Ss received the CS-US pairings and, wherc appropriate, the ensuing extinction trials. The CS was a 30-sec $82-\mathrm{dB}$ white noise. The US was $.5 \mathrm{sec}$ in duration and of the appropriate intensity. CS and US were coterminous. Each session began when the drinking tube was remotely inserted into the chamber. Unless otherwise specified. CS onset occurred on the average of $3 \mathrm{~min}$ (range $=2.4 \mathrm{~min}$ ) after each session began.

Responses were recorded and summarized during pre-CS and
CS periods. The pre-CS was a 30 -sec period occurring immediately prior to the CS. Data analysis was performed on pre-CS scores, CS scores, and on suppression ratios. The suppression ratios were calculated by dividing $C S$ scores by the sum of pre-CS and CS scores. A suppression ratio of 0.5 indicates no suppression during the $C S$, while a zero suppression ratio indicates complete suppression. A suppression ratio of zero was assigned when complete response suppression occurred during the pre-CS.

\section{EXPERIMENT I}

The purpose of Experiment I was to assess how spacing of trials under various shock intensities would affect acquisition.

\section{Method}

\section{Subjects and Procedure}

Of the 64 Ss, 8 were assigned unsystematically to each of eight groups. The experimental design was essentially a 2 by 4 factorial, with either one or two daily CS-US pairings and four levels of shock intensity: $0.1,0.5,1.0$, or $2.0 \mathrm{~mA}$. For groups receiving two daily trials, the within-session intertrial interval was $3 \mathrm{~min}$.

\section{Results and Discussion}

Each panel of Fig. 1 illustrates acquisition performance at a single shock intensity. Groups receiving one trial or two trials a day are plotted across the odd-numbered trials. To equate the time in the session when the CS-US pairing occurred, the first daily trial was used for the two-trials-a-day groups and the corresponding ordinal trials for the one-trial-a-day groups. Thus, for the one-trial-a-day groups, performance on alternate days is shown in Fig. 1 . Groups by Trials ANOVAs ( 2 by 5 ) for each shock intensity yielded no group differences or Groups by Trials interaction for suppression ratios, CS responses, or pre-CS responses, with the exception of a marginally significant difference in the suppression ratio data for the 0.5 -mA group $(F=4.64$, df $=1 / 14, p<.05)$. The trials main effects for suppression ratios were significant at $\mathrm{p}<.001$ for all shock intensities except $0.1 \mathrm{~mA}$, in which case the $p$ value was .025 . These analyses indicate that learning occurred at each shock intensity and that performance varied as a function of number of trials but did not differ as a result of presenting one or two trials a day. The exception was the $0.5 \cdot \mathrm{mA}$ group where two daily trials appeared to produce a higher level of response suppression as compared to one daily trial.

\section{EXPERIMENT II}

In this experiment, the effects of one or two daily trials at a shock intensity of $0.5 \mathrm{~mA}$ were examined again in an attempt to assess the reliability of the differences between these groups found in Experiment I. 


\section{Method}

\section{Subjects and Procedure}

The Ss were 23 rats. The procedure was similar to that of Experiment 1 . With a shock intensity of $0.5 \mathrm{~mA} .12$ S、 recicis ed one CS-US pairing on each acquisition day; 11 Ss received two pairings each day.

\section{Results and Discussion}

The results. depicted in Fig. 2. are clear in demonstrating no difference between the one-trial and two-trials groups. Neither the groups main effect nor the Groups by Trials interaction was significant (Fs $<1$ ). but the trials effect was reliable $(\mathrm{p}<.001)$. For pre-CS scores, neither the group differences $(F=1.91$. $d f=$ $1 / 21, p>.10)$ nor the Groups by Trials interaction $(F=$ $1.56, \mathrm{df}=4 / 84, \mathrm{p}>.10$ ) was significant.

Experiments I and II taken together are consistent with the results of Carlton and Vogel (1967. Experiment 3), who also found no difference in CER strength following one or two daily CS-US pairings. The present data extend the findings of Brimer and Dockrill (1966).

However, the present results tend not to support Beecroft's (1967, p. 51) suggestion that optimal conditioning of fear may occur on a conditioning schedule of one trial per day. One or two trials per day yield the fastest acquisition, while four daily trials result in comparatively slower conditioning (Brimer \& Dockrill. 1966). Beecroft's further speculation that one conditioning trial, in contrast to two or more, may result in less reduction in baseline responding was not

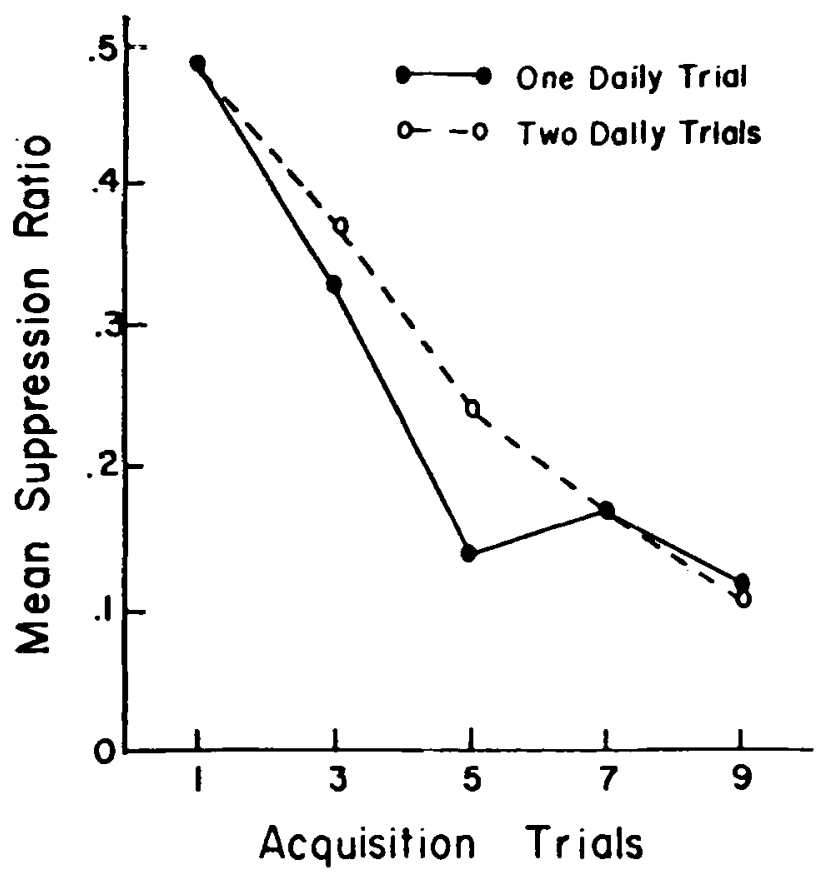

Fig. 2. Mean suppression ratios across the odd-numbered acquisition trials as a function of daily trials.

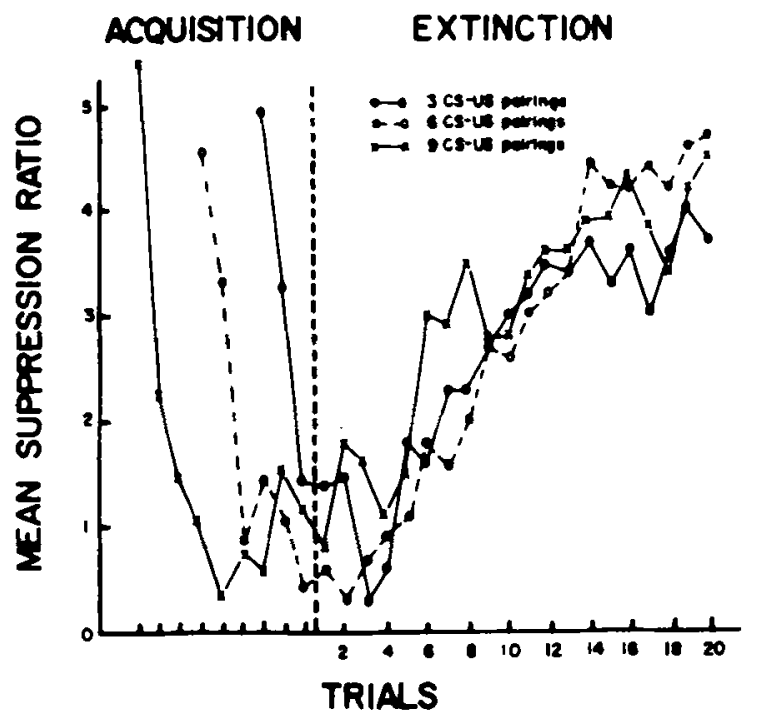

Fig. 3. Mean suppression ratios across acquisition and extinction trials as a function of number of CS-US pairings.

supported by the present findings. Pre-CS responding did not differ between the one- and two-trials-per-day groups.

\section{EXPERIMENT III}

The purpose of this experiment was to investigate the relationship between number of CS-US pairings and resistance to extinction. Experiment I indicated that for the $1.0-\mathrm{mA}$ one-trial-a-day group, maximum response suppression occurred sometime after the second CS-US pairing. It has been shown, however, that conditioned suppression performance during acquisition does not always accurately predict extinction behavior (e.g., Annau \& Kamin, 1961). Even though three of their groups showed maximum undifferentiated suppression during acquisition, differential resistance to extinction was demonstrated. In addition, Kamin, Brimer, and Black (1963) found that resistance to extinction was maximal following nine CS-US pairings. In view of these findings, Experiment III examined extinction behavior following three, six, or nine daily CS-US pairings.

\section{Method}

\section{Subjects and Procedure}

The Ss were 34 rats. One CS-US pairing was presented on each day of acquisition, and one CS-alone trial was administered on each day of extinction. Shock intensity was $0.8 \mathrm{~mA}$. Ten Ss received three acquisition trials, $12 \mathrm{Ss}$ received six acquisition trials, and another $12 \mathrm{Ss}$ received nine acquisition trials. On the day following the final acquisition trial, the first of 20 extinction trials was administered.

\section{Results and Discussion}

Figure 3 shows mean suppression ratios plotted across acquisition and extinction trials for groups receiving 


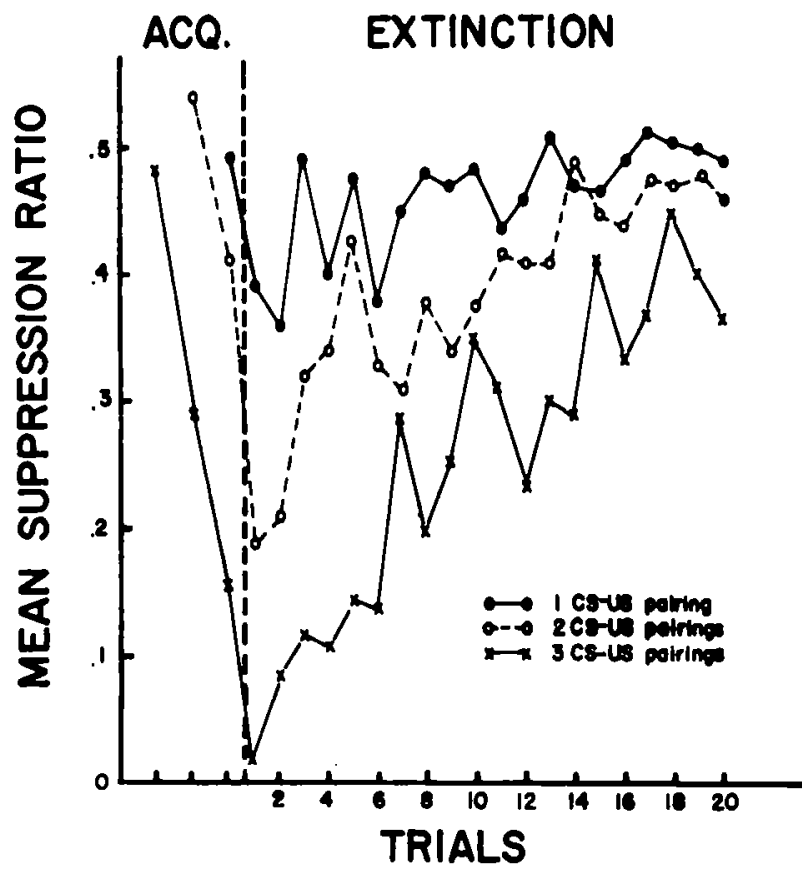

Fig. 4. Mean suppression ratios across acquisition and extinction trials as a function of number of CS-US pairings.

three, six, or nine acquisition trials. A tests (Sandler, 1955) on the acquisition performance of all Ss indicated that a significant increment in response suppression occurred across Trials 1 and $2(\mathrm{~A}=.083$, $\mathrm{df}=31$, $\mathrm{p}<.001)$ and across Trials 2 and $3(\mathrm{~A}=.005, \mathrm{df}=31$, $\mathrm{p}<.001)$, but not across Trials 3 and $4(\mathrm{~A}=1.44)$. Response suppression on the first extinction trial reflects the terminal acquisition performance of each group. ANOVA on suppression ratios of the first day of extinction indicated no differences in performance $(\mathrm{F}=$ 1.11). Groups by Trials ( 3 by 20) ANOVAs failed to yield significant group differences for suppression ratios, CS scores, or pre-CS scores, but trials were highly significant $(p<.001)$. The interaction of Groups by Trials was not significant. These results suggest that maximum conditioning of response suppression, reflected by acquisition performance and resistance to extinction, occurred by Trial 3 .

\section{EXPERIMENT IV}

This experiment attempted to investigate resistance to extinction as a function of one, two, or three CS-US pairings.

\section{Method}

\section{Subjects and Procedure}

The Ss were 39 rats. The procedure was similar to Experiment III, except different groups of $13 \mathrm{Ss}$ each received one, two, or three acquisition trials.
Results and Discussion

Figure 4 illustrates performance across the acquisition and extinction trials. On the first extinction trial, the groups differed significantly $(F=24.79$, $\mathrm{df}=2 / 36$, $\mathrm{p}<.001)$. Individual $t$ tests indicated that the three-trials group suppressed more on the first extinction trial than did the two-trials group, which differed significantly from the one-trial group $(p<.01$ for both comparisons). The results of a 3 by 20 ANOVA (number of pairings by extinction trials) yielded significant $F$ ratios $(\mathrm{p}<.001)$ for number of pairings $(\mathrm{F}=21.51, \mathrm{df}=$ $2 / 36)$, for extinction trials $(F=14.62, \mathrm{df}=19 / 684)$, and for the Number of Pairings by Extinction Trials interaction $(F=2.40, \mathrm{df}=38 / 684)$. In addition to Extinction Trial 1 , by individual $t$ tests $(p<.05)$, the one-trial and two-trial groups differed on Extinction Trials 2-6, and the one-trial and three-trial groups differed on Extinction Trials 2-14.

The results of Experiments III and IV suggest that resistance to extinction is positively related to number of CS-US pairings, with maximum conditioning of response suppression occurring as a result of three trials. These findings further show that extinction performance can be adequately predicted from the terminal level of acquisition.

\section{CONCLUSIONS}

The major findings suggested by the present experiments are listed as follows: First, spacing of CS-US pairings appeared not to affect either acquisition performance or baseline responding. Second, performance during acquisition as well as resistance to extinction were increasing functions of number of CS-US pairings. Under the restricted conditions of these experiments, resistance to extinction reached a maximum value following three CS-US pairings. Finally, resistance to extinction could be reliably predicted from differential terminal acquisition performance produced by varying the numbers of CS-US pairings.

\section{REFERENCES}

Annau, Z., \& Kamin, L. J. The conditioned emotional response as a function of the intensity of the US. Journal of Comparative \& Physiological Psychology, 1961, 54, 428-432.

Beecroft, R. S. Emotional conditioning. Psychonomic Monograph Supplements, 1967, 2, 45-72.

Brimer, C. J., \& Dockrill, F. J. Partial reinforcement and the CER. Psychonomic Science, 1966, 5. 185-186.

Carlton, P. L., \& Vogel, J. R. Habituation and conditioning. Journal of Comparative \& Physiological Psychology, 1967,63, 348-351.

Hendry, D. P., \& Van Toller, C. Alleviation of conditioned suppression. Journal of Comparative \& Physiological Psychology. 1965, 59, 458-460. 
Kamin, L. J., Brimer, C. J.. \& Black. A. H. Conditioned suppression as a monitor of fear of the $C S$ in the course of avoidance training. Journal of Comparative \& Physiological Psychology. 1963.56.497-501.

Leaf. R. C.. \& Muller. S. A. Simple method for CER conditioning and measurement. Psychological Reports, 1965, 17, 211-215.

Libby, A. Two variables in the acquisition of depressant properties by a stimulus. Journal of Experimental Psychology, 1951, 42. 100-107.

Sandler. J. A test of the significance of the difference between the means of correlated measures. based on a simplification of the Student's t. British Journal of Psychology, 1955, 46. 225-226.

Strouthes, A. Effect of CS-onset UCS-termination delay, LCS duration, CS-onset UCS-onset interval, and number of CS-US pairings on conditioned fear response. Journal of Experimental Psychology, 1965, 69, 287-291.

Strouthes, A., \& Hamilton, H. C. UCS intensity and number of CS-UCS pairings as determiners of conditioned fear response. Psychological Reports, 1964, 15, 707-714.

(Received for publication October 25, 1972; revision recejved January 15,1973 .) 